Check for updates

Cite this: RSC Adv., 2019, 9, 6409

\title{
Reactive intermediates in copanlisib metabolism identified by LC-MS/MS: phase I metabolic profiling $\dagger$
}

\author{
Haitham AlRabiah, ${ }^{a}$ Adnan A. Kadi, ${ }^{a}$ Mohamed W. Attwa, (D) *ab Ali S. Abdelhameed (D) ${ }^{a}$ \\ and Gamal A. E. Mostafaac
}

Copanlisib (CNB; AliqopaTM) is a novel, intravenous phosphoinositide 3-kinase inhibitor used to treat various solid and hematological malignancies. CNB was recently approved by the U.S. FDA to treat adults that relapsed after two preceding systemic therapies. Using LC-MS/MS, we screened for the in vitro metabolites of CNB formed in human liver microsomes (HLMs) and probed for the generation of reactive electrophiles using methoxyamine and potassium cyanide as nucleophiles to capture reactive electrophiles by forming stable adducts that are suitable for identification by LC-MS/MS. Seven CNB phase I metabolites generated by oxidation, hydroxylation, oxidative dealkylation, reduction, and $N$ oxidation were identified. In addition, four reactive electrophiles, 2 aldehydes and 2 iminium ions, were identified, and a prediction of the corresponding bioactivation mechanism is presented. The formation of reactive metabolites may be associated with the side effects reported for CNB. To our knowledge, this is the first report on the detailed structural characterization of reactive intermediates generated in $\mathrm{CNB}$ metabolism.

Received 16th December 2018 Accepted 11th February 2019

DOI: $10.1039 / c 8 r a 10322 d$

rsc.li/rsc-advances
Copanlisib (CNB) is a potent class I PI3K inhibitor with preferential activity against $\mathrm{p} 110 \alpha$ and $\mathrm{p} 110 \delta$ than $\mathrm{p} 110 \beta$ and p110 $\gamma$. CNB is a novel, intravenous PI3K inhibitor used to treat different solid and hematological malignancies. ${ }^{9,10}$ CNB induces tumor cell death such as apoptosis, and inhibits primary malignant B cell proliferation and tumor growth in the preclinical xenograft tumor models of malignant B cell. ${ }^{11}$

CNB (Aliqopa ${ }^{\mathrm{TM}}$ ) is approved by the U.S. Food and Drug Administration for the treatment of adults who relapsed after two prior treatments with systemic therapies. ${ }^{12}$ Common toxic side effects of CNB include weakness, hypertension, hyperglycemia, diarrhea, nausea, low levels of specific white blood cells (leukopenia, neutropenia), low levels of blood platelets, and lower respiratory tract infections. ${ }^{\mathbf{1 3}}$

Metabolic detoxification involves pathways that transform endogenous compounds and xenobiotics into more hydrophilic species to facilitate excretion from the human body. The generated metabolites are often less toxic than the parent molecules but in some cases, bioactivation may occur and promote reactive electrophile formation which leads to more toxic metabolites. ${ }^{\mathbf{1 4 - 1 6}}$ Reactive electrophiles are electron deficient and can modify proteins and DNA by forming covalent bonds; this is considered the first step in drug-mediated organ toxicities. ${ }^{17,18}$ Verifying reactive metabolite production is a critical task in the study of drug-induced toxicity. Reactive metabolites are often formed by phase-I metabolic reactions and cannot be directly characterized because of their transient nature. Instead, a trapping agent can be used to capture reactive
${ }^{a}$ Department of Pharmaceutical Chemistry, College of Pharmacy, King Saud University, P. O. Box 2457, Riyadh, 11451, Saudi Arabia. E-mail: mzeidan@ksu.edu.sa; Fax: +966 114676 220; Tel: +966114670237

${ }^{b}$ Students' University Hospital, Mansoura University, Mansoura 35516, Egypt ${ }^{c}$ Micro-analytical Lab, Applied Organic Chemistry Department, National Research Center, Dokki, Cairo, Egypt

$\dagger$ Electronic supplementary information (ESI) available. See DOI: 10.1039/c8ra10322d 
<smiles>COc1c(OCCCN2CCOCC2)ccc2c1N=C(NC(=O)c1cnc(N)nc1)N1CCN=C21</smiles>

Fig. 1 Chemical structure of copanlisib.

intermediates via the formation of stable adducts that can be identified by mass spectrometry. ${ }^{19,20}$

The structure of CNB, 2-amino- $N$ - $\{7-$ methoxy-8-[3-(4 morpholinyl)propoxy]-2,3-dihydroimidazo[1,2-c]quinazolin-5-yl\}-5pyrimidinecarboxamide (Fig. 1), contains a morpholine moiety (cyclic tertiary amine ring) that can undergo bioactivation by iminium ion generation or oxidative dealkylation to form aldehyde intermediates. ${ }^{21-24}$ Glutathione and its derivatives are highly nucleophilic and react poorly with strong electrophiles. ${ }^{25}$ However, the iminium ion and aldehydes are electrophiles that can be trapped using potassium cyanide and methoxyamine, respectively. ${ }^{14,21,22}$ The adducts formed by nucleophilic-electrophilic interactions are considered stable and can be separated and identified by LC-MS/MS. ${ }^{19-21,26,27}$ We hypothesized that these reactive intermediates are potentially involved in the reported side effects of CNB.
Literature review showed a single article that described the pharmacokinetics and disposition of CNB in human volunteers, ${ }^{28}$ without addressing the structural identification of the formed metabolites or reactive intermediate formation. Therefore, the aim of the current work is to identify the bioactivation pathways of CNB resulting in reactive intermediates as can only be captured via in vitro experiments. While in vivo, these compounds have the capability to bind covalently to DNA and protein molecules and become undetectable. ${ }^{17,20,26,29}$

\section{Chemicals and methods}

\subsection{Chemicals}

All chemical and solvents used were of analytical grade. CNB was procured from Med Chem. Express (USA). Acetonitrile, methoxyamine, ammonium formate, pooled human liver microsomes (HLMs, M0567) potassium cyanide and formic acid were procured from Sigma-Aldrich (USA). HPLC grade water $\left(\mathrm{H}_{2} \mathrm{O}\right)$ was purchased from Milli-Q plus system (USA).

\subsection{Chromatographic conditions}

Parameters used for chromatographic separation of the HLM incubation mixture are shown in Table 1.

\subsection{HLM incubation}

Several concentrations from 5 to $30 \mu \mathrm{M}$ were analyzed; however, the only change observed was an increase in the concentration of metabolites to allow easier identification. Screening for in vitro metabolites of CNB was performed by incubating $30 \mu \mathrm{M}$ CNB with $1.0 \mathrm{mg} \mathrm{mL}^{-1}$ HLMs in phosphate buffer $(50 \mathrm{mM}, \mathrm{pH}$ 7.4 ) and $3.3 \mathrm{mM} \mathrm{MgCl}_{2}$. Incubation time and temperature were $2 \mathrm{~h}$ and $37^{\circ} \mathrm{C}$, respectively. The samples were incubated in a shaking water bath. The CNB metabolic reactions were initiated by adding NADPH $(1.0 \mathrm{mM})$ and stopped by adding $2 \mathrm{~mL}$ ice-cold acetonitrile. Protein precipitates were removed by centrifugation at $9000 \mathrm{~g}\left(15 \mathrm{~min}, 4{ }^{\circ} \mathrm{C}\right)$ and the supernatants

Table 1 LC-MS/MS optimized parameters

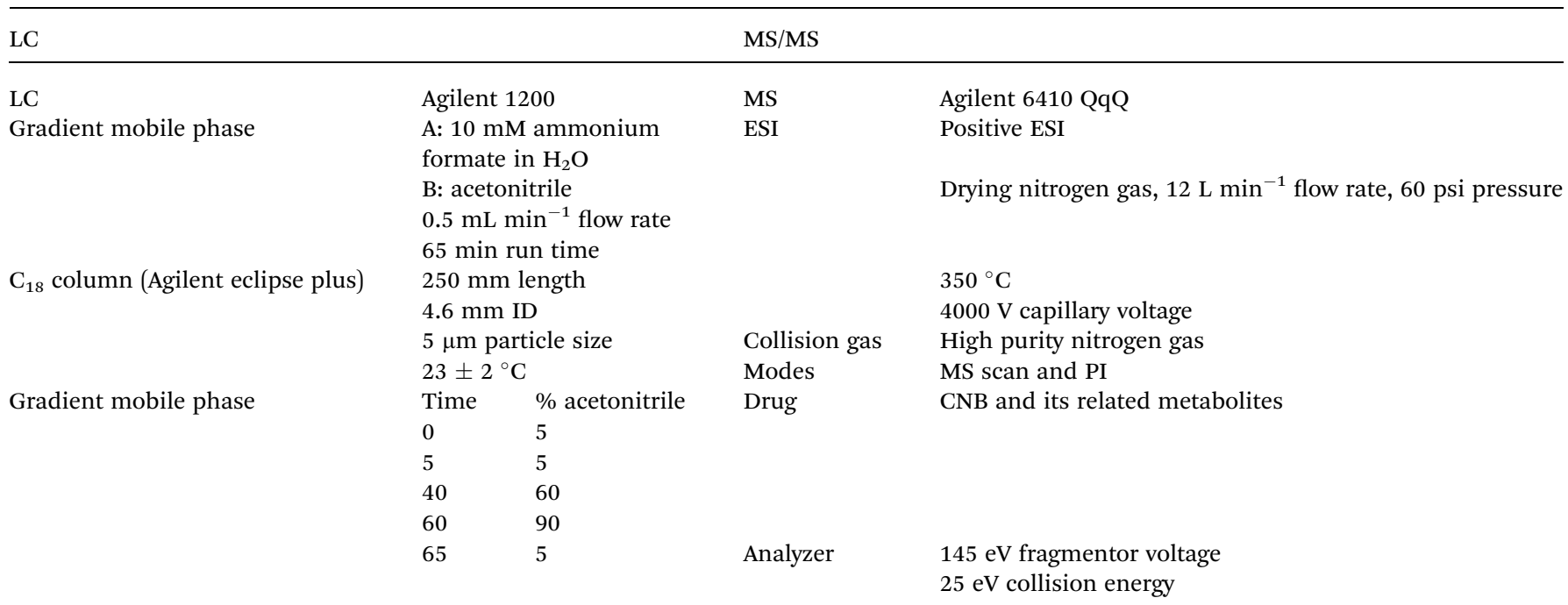




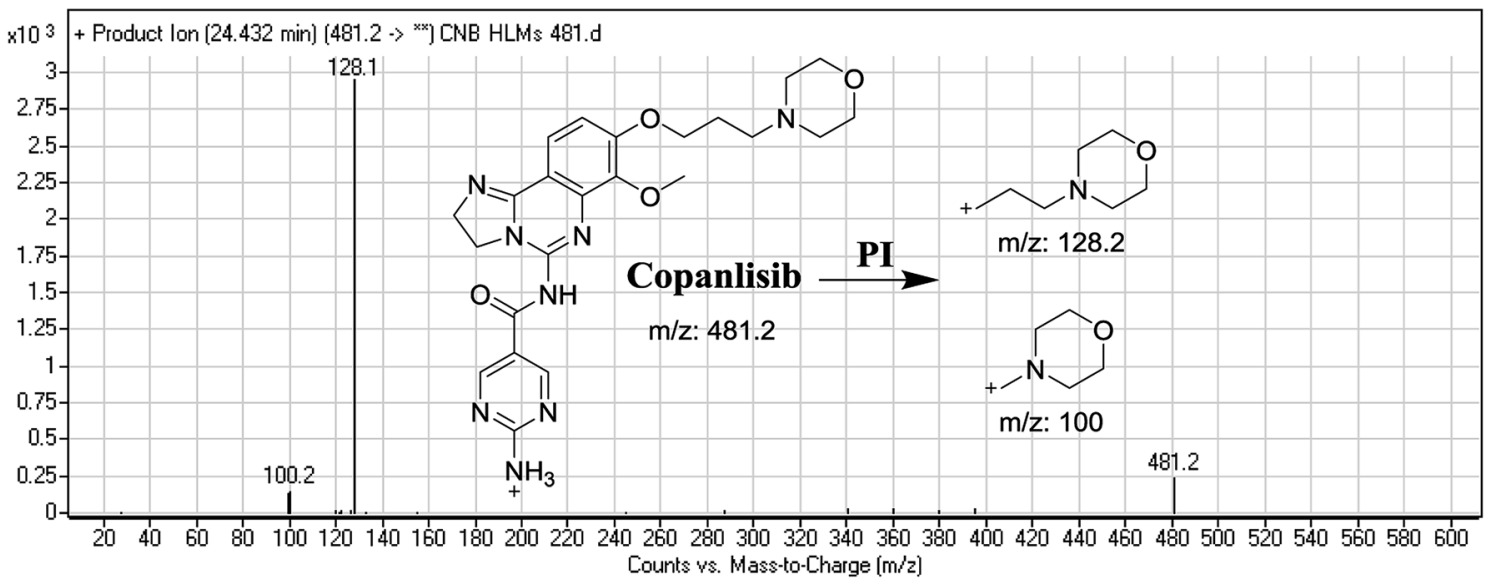

Fig. 2 Mass spectrum of copanlisib and its MS/MS fragments.

were evaporated then reconstituted in the mobile phase. Aliquots of $10 \mu \mathrm{L}$ of each reconstituted sample were analyzed using LC-MS/MS system..$^{30-32}$ Replicates of blank sample were analyzed at the same run to confirm the absence of the proposed metabolites or adducts (ESI Fig. S11-S20†).

\subsection{Identification of CNB reactive metabolites}

Full MS scans and extracted ion chromatograms of select $\mathrm{m} / \mathrm{z}$ peaks were used to identify in vitro metabolites from the incubation chromatograms; molecular ions served as precursor ions (PIs) for fragmentation into daughter ions (DIs). Fragmentation (F) patterns were used to characterize in vitro metabolites and reactive intermediates generated by CNB metabolism.

The same HLM incubation assay was repeated in the presence of methoxyamine or potassium cyanide to trap bioactive electrophiles. Reactions were performed in triplicate.

\section{Results and discussion}

\subsection{Fragmentation analysis of CNB}

The CNB precursor ion peak (PIP) appeared at $24.4 \mathrm{~min}$. F of PI at $m / z 481$ resulted in two DRs at $m / z 128$ and $m / z 100$, representing alkyl morpholine rings (Fig. 2).

\subsection{Identification of $\mathrm{CNB}$ in vitro metabolites and reactive intermediates}

Purified extracts recovered from HLM assays were subjected to LC triple-quadrupole MS (LC-QqQ MS) from which, three new phase I metabolites (M499, M483a, and M497a) and 4 reactive metabolites were identified. Six metabolites were produced from seven phase I metabolic reactions namely, ( $\alpha$-hydroxylation, $\alpha$-oxidation, reduction, oxidative dealkylation, and $N$ oxidation. In addition, two cyano and 2 methoxyamine adducts were identified (Table 2).

Table 2 Phase I and reactive metabolites of copanlisib

\begin{tabular}{|c|c|c|c|c|}
\hline & MS scan & Most abundant fragment ions & Retention time (min) & Metabolic reaction \\
\hline CNB & 481 & 128,100 & 24.4 & \\
\hline
\end{tabular}

\section{Phase I metabolites}

$\begin{array}{llll}\text { M497a } & 497 & 479,358,128 & 23.4 \\ \text { M497b } & 497 & 479,144,126 & 23.8 \\ \text { M495 } & 495 & 142,233,354 & 28.0 \\ \text { M455 } & 455 & 102,233,354 & 23.0 \\ \text { M483a } & 483 & 100,128,361 & 24.1 \\ \text { M483b } & 483 & 130,233,354 & 26.1 \\ \text { M499 } & 499 & 100,128,361 & 22.7\end{array}$

Reactive metabolites

$\begin{array}{llll}\text { M506 } & 506 & 479,354,126,98 & 32.6 \\ \text { M508 } & 508 & 481,356,260,126,98 & 32.7 \\ \text { M439 } & 439 & 354,122,94 & 51.5 \\ \text { M512 } & 512 & 354,272,131 & 37.2\end{array}$

Hydroxylation of 2,3-dihydroimidazole ring $\alpha$-Hydroxylation at morpholine ring $\alpha$-Oxidation Ring cleavage and dealkylation Reduction at 2,3-dihydroimidazole Morpholine ring cleavage, oxidative dealkylation. Reduction of dihydroimidazole ring \& $\mathrm{N}$-oxidation of pyrimidine ring

Cyano addition

Reduction and cyano addition

Methoxyamine oximer formation

Oxidative dealkylation of morpholine ring then methoxyamine oximer formation 

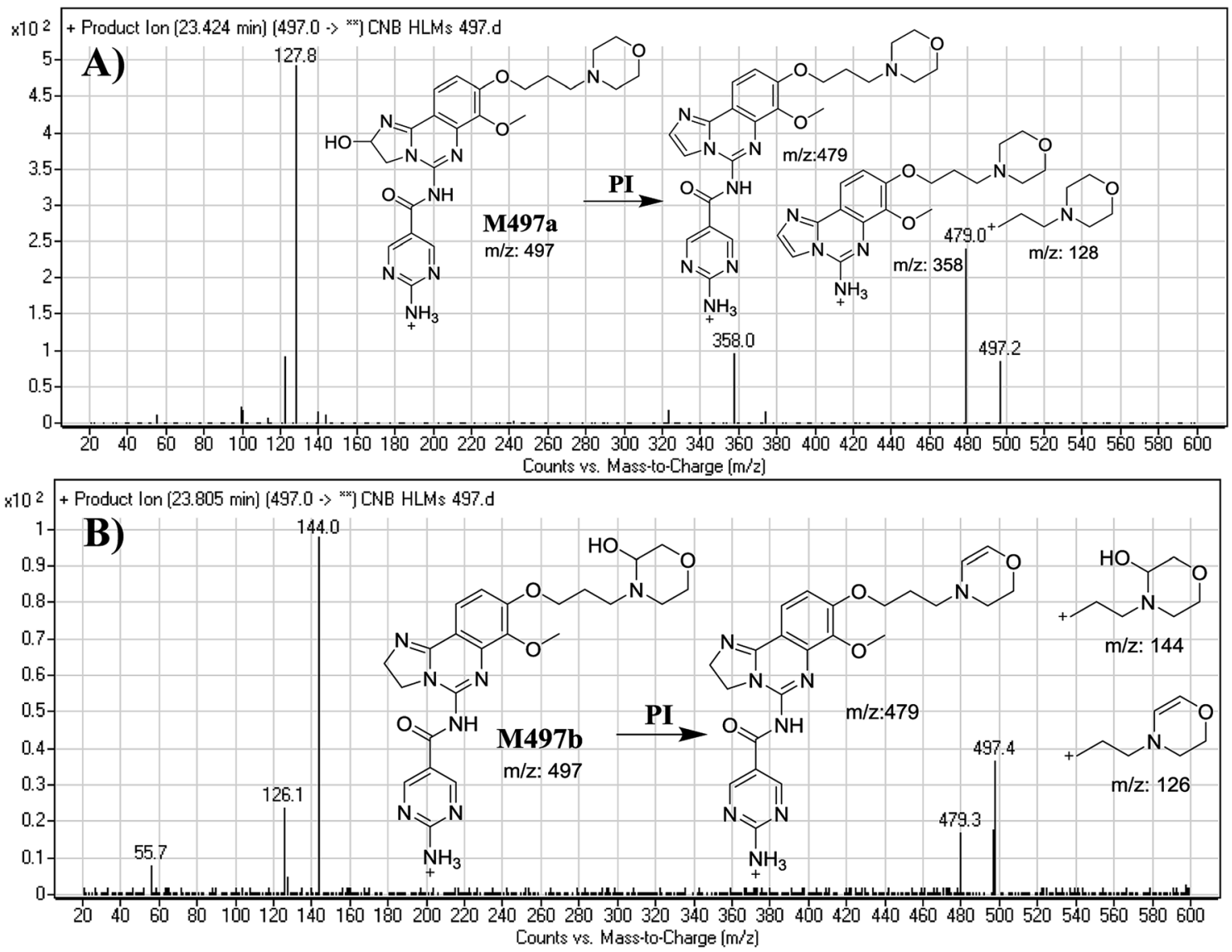

Fig. 3 Mass spectra of M497a (A) and M497b (B), and their MS/MS fragments.

3.2.1. Identification of M497a and M497b phase I metabolite of CNB. M497a and M497b PIPs appeared at $23.4 \mathrm{~min}$ and $23.8 \mathrm{~min}$, respectively. F of PI at $\mathrm{m} / \mathrm{z} 497$ produced different DRs (Fig. 3A and B).

The F of M497a resulted in three DRs at $\mathrm{m} / \mathrm{z} 479, \mathrm{~m} / \mathrm{z} 358$, and $\mathrm{m} / \mathrm{z} 128$ (Fig. 3A), all containing the alkyl morpholine ring. The DR at $m / z 128$ suggested the absence of a metabolic change in the morpholine moiety. DRs revealed that M497a is a hydroxylated form of CNB with a 2,3-dihydroimidazole ring matching the DR at $m / z 358$ (Fig. 3A).

The F of M497b resulted in three DRs at $\mathrm{m} / \mathrm{z} 479, \mathrm{~m} / \mathrm{z} 144$, and $m / z 126$ (Fig. 3B). The DR at $m / z 142$ represented the alkyl hydroxyl morpholine ring produced by single bond cleavage which matches the DR at $m / z$ 126. Hydroxylation was predicted to occur in the $\alpha$-position of the morpholine nitrogen $(\mathrm{N})$ atom (Fig. 3B).

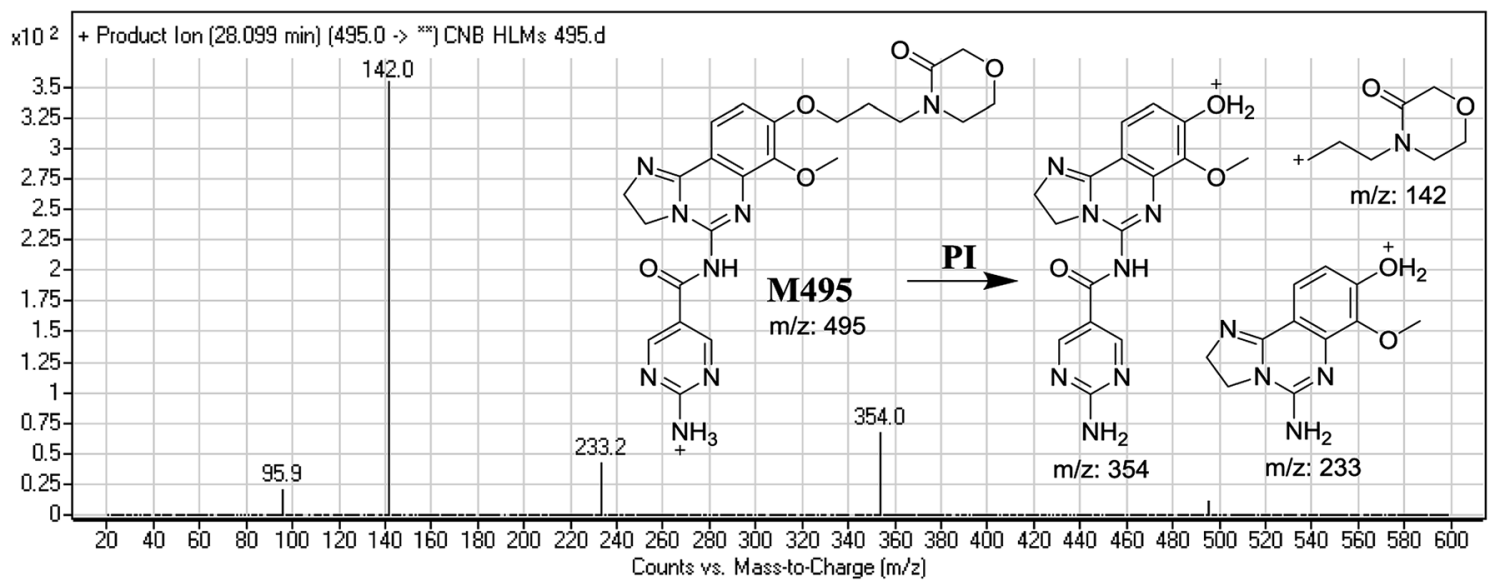

Fig. 4 Mass spectrum of M495 and its MS/MS fragments. 


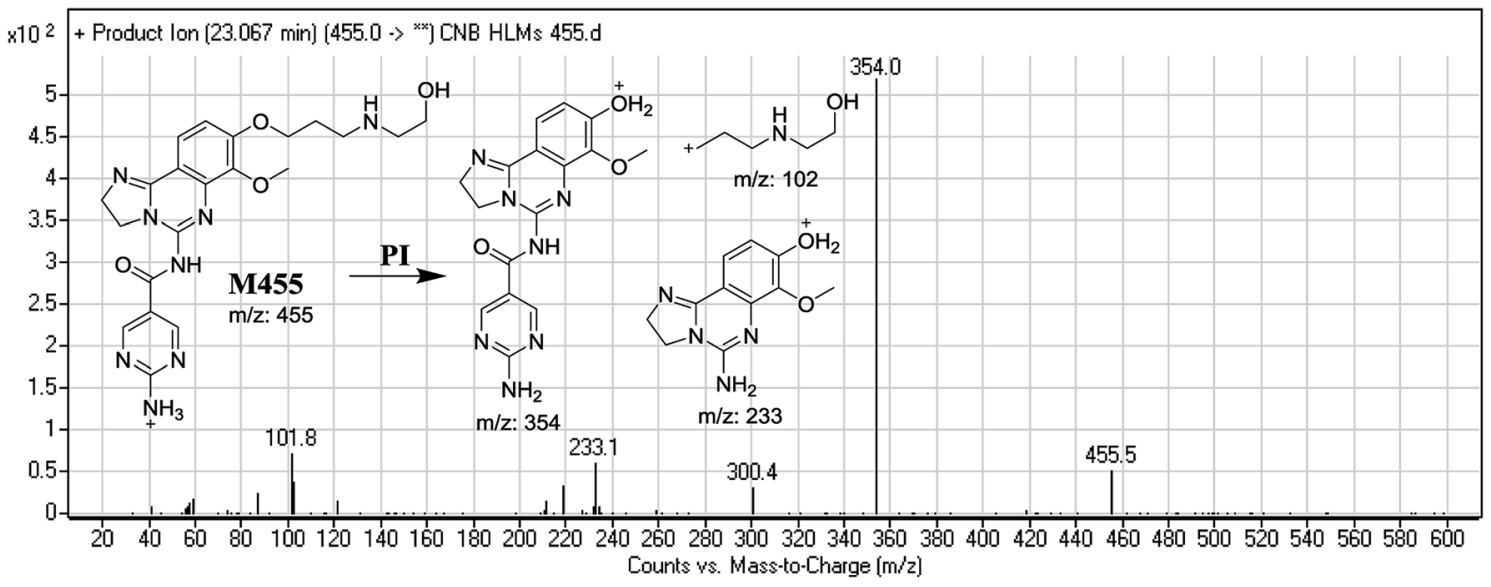

Fig. 5 Mass spectrum of M455 and its MS/MS fragments.

3.2.2. Identification of M495 phase I metabolite of CNB. M495 PIP appeared at $28.0 \mathrm{~min}$. F of PI at $\mathrm{m} / \mathrm{z} 495$ resulted in three DRs at, $m / z$ 354, and $m / z 233, m / z$ 142. DR at $m / z 142$ represented an alkyl keto morpholine ring matching the other ions at $\mathrm{m} / \mathrm{z} 354$ and $\mathrm{m} / \mathrm{z} 233$. Oxidation was predicted to occur at the $\alpha$-position of the morpholine $\mathrm{N}$ atom (Fig. 4).
3.2.3. Identification of M455 phase I metabolite of CNB. M455 PIP appeared at $23.0 \mathrm{~min}$. F of PI at $\mathrm{m} / \mathrm{z} 455$ resulted in three DRs at $m / z 354$, and $m / z 233, m / z 102$. DR at $m / z 102$ represented the cleaved morpholine ring and dealkylation of the ethyl moiety matching that of other ions at $\mathrm{m} / \mathrm{z} 354$ and $\mathrm{m} / \mathrm{z} 233$. Ring cleavage and dealkylation were predicted to occur at the morpholine ring (Fig. 5).

:102 + Product lon (24.123 min) (483.0 - " " CNB HLMs 483.d

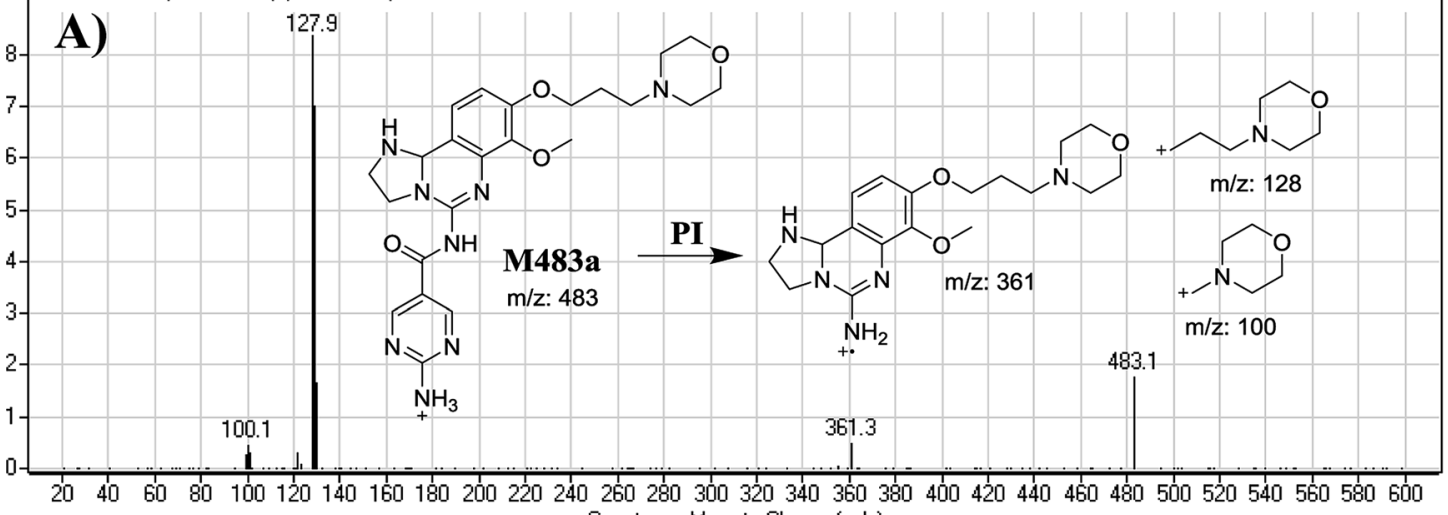

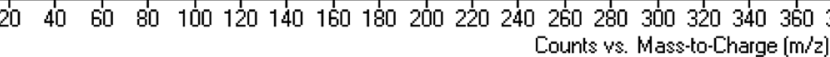

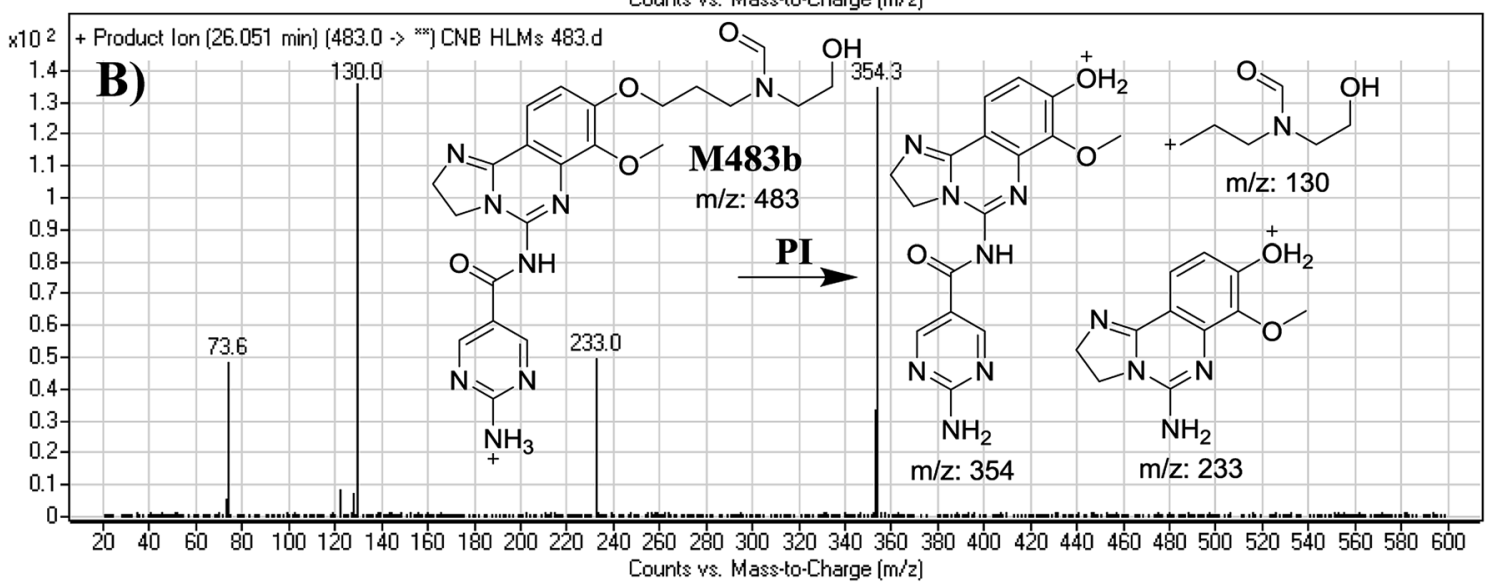

Fig. 6 Mass spectra of M483a (A) and M483b (B) and their MS/MS fragments. 


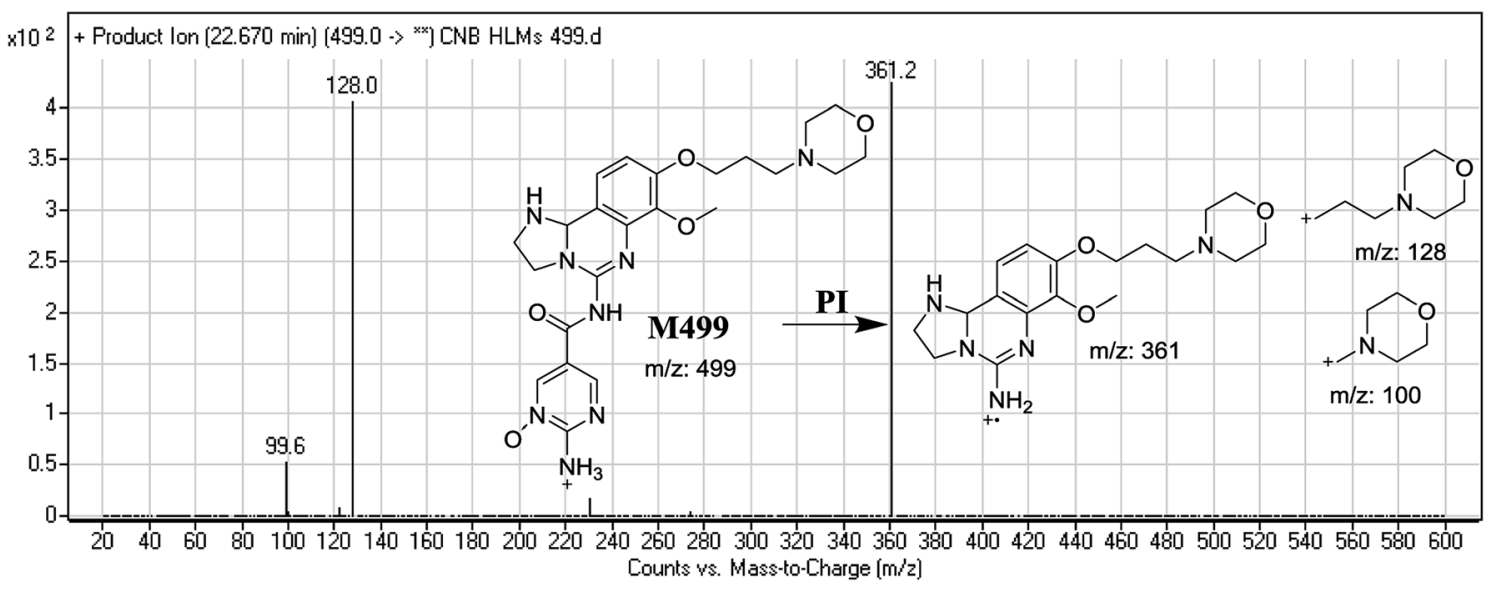

Fig. 7 Mass spectrum of M499 and its MS/MS fragments.

3.2.4. Identification of M483a and M483b phase I metabolites of CNB. M483a and M483b PIPs appeared at $24.1 \mathrm{~min}$ and $26.1 \mathrm{~min}$, respectively. F of PI at $m / z 483$ generated different DRs (Fig. 6A and B).

F of M483a resulted in three DRs at $m / z 361, m / z 128$ and $m / z$ 100 (Fig. 6A), which represents the alkyl morpholine ring produced by single bond cleavage. DR at $m / z 128$ suggested that no metabolic change occurred at the morpholine ring. DRs revealed that $\mathrm{M} 483 \mathrm{a}$ is a reduced form of $\mathrm{CNB}$ at the 2,3-dihydroimidazole ring (Fig. 6A).

F of M483b resulted in three DRs at $\mathrm{m} / \mathrm{z} 354, \mathrm{~m} / \mathrm{z} 233$, and $\mathrm{m} / \mathrm{z}$ 130 (Fig. 6B). DR at $m / z 130$ suggested that metabolic changes occurred in the morpholine ring matching the other DR at $\mathrm{m} / \mathrm{z}$ 354. Ring cleavage and oxidative dealkylation were predicted to occur at the morpholine ring (Fig. 6B).

3.2.5. Identification of M499 phase I metabolite of CNB. M499 PIP appeared as $[\mathrm{M}+\mathrm{H}]^{+}(\mathrm{m} / z$ 499) at $22.7 \mathrm{~min}$. F of PI at $\mathrm{m} / \mathrm{z} 499$ resulted in DRs at $\mathrm{m} / \mathrm{z} 128$ and $\mathrm{m} / \mathrm{z} 100$, indicating the absence of a metabolic reaction at the morpholine ring. DR at $\mathrm{m} / \mathrm{z} 361$ suggested that reduction occurred in the dihydroimidazole ring whereas $N$-oxidation occurred at the pyrimidine ring (Fig. 7).

\subsection{Reactive metabolites}

Two cyano and 2 methoxyl adducts were identified after incubating CNB with HLMs in the presence of trapping agents.

3.3.1. Identification of M506 cyano conjugate of $\mathrm{CNB}$. M506 PIP appeared at $32.6 \mathrm{~min}$. F of PI at $\mathrm{m} / z 506$ resulted in DRs at $\mathrm{m} / \mathrm{z} 479, \mathrm{~m} / \mathrm{z} 354, \mathrm{~m} / \mathrm{z} 126$, and $98 \mathrm{~m} / \mathrm{z}$. DR at $\mathrm{m} / \mathrm{z} 479$ indicated the loss of a hydrogen cyanide group. DR at $m / z 126$ suggested the addition of a cyanide ion at the activated $\alpha$-carbon of the $\mathrm{N}$ atom on the morpholine ring (Fig. 8).

3.3.2. Identification of M508 cyano conjugate of CNB. M506 PIP appeared at $32.7 \mathrm{~min}$. F of PI at $\mathrm{m} / \mathrm{z} 508$ resulted in DRs at $\mathrm{m} / \mathrm{z} 481, \mathrm{~m} / \mathrm{z} 356, \mathrm{~m} / \mathrm{z} 126$, and $\mathrm{m} / \mathrm{z} 98$. DR at $\mathrm{m} / \mathrm{z} 481$ indicated the loss of a hydrogen cyanide group. DRs at $m / z 356$ and $m / z 260$ suggested that a reduction occurred on the pyrimidine ring. DR at $\mathrm{m} / \mathrm{z} 126$ suggested that the addition of a cyanide ion occurred at the activated $\alpha$-carbon of the $\mathrm{N}$ atom on the morpholine ring (Fig. 9).

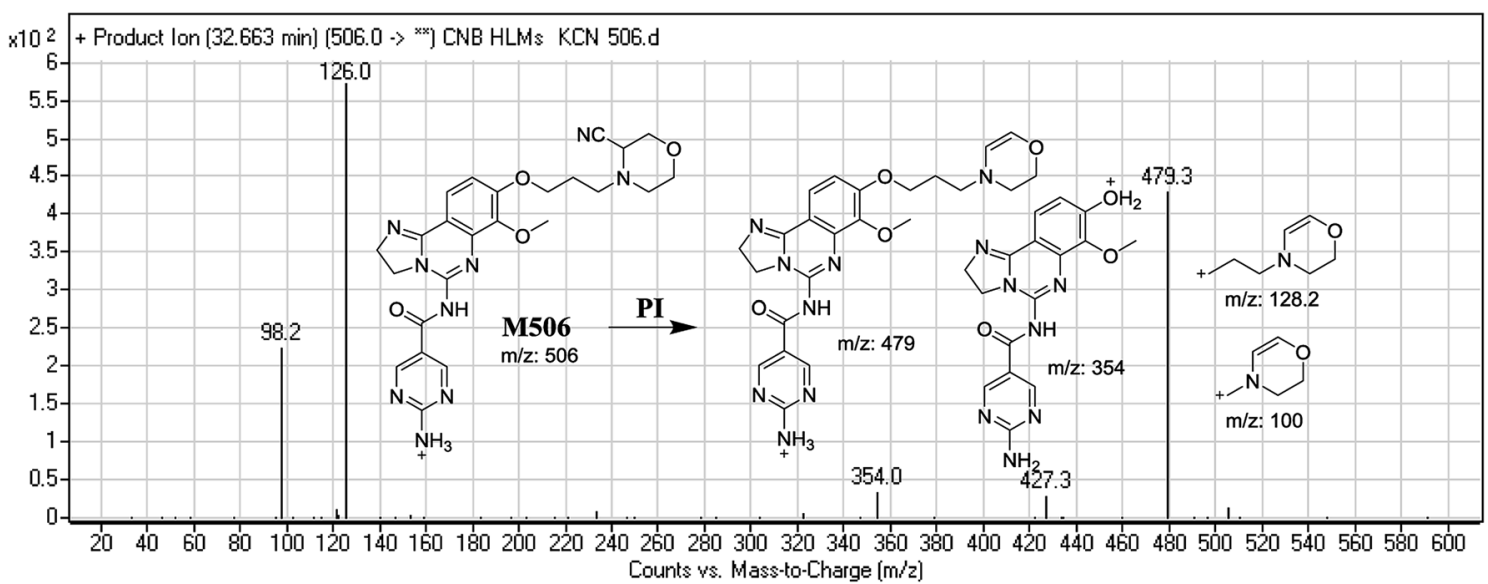

Fig. 8 Mass spectrum of M506 and its MS/MS fragments. 


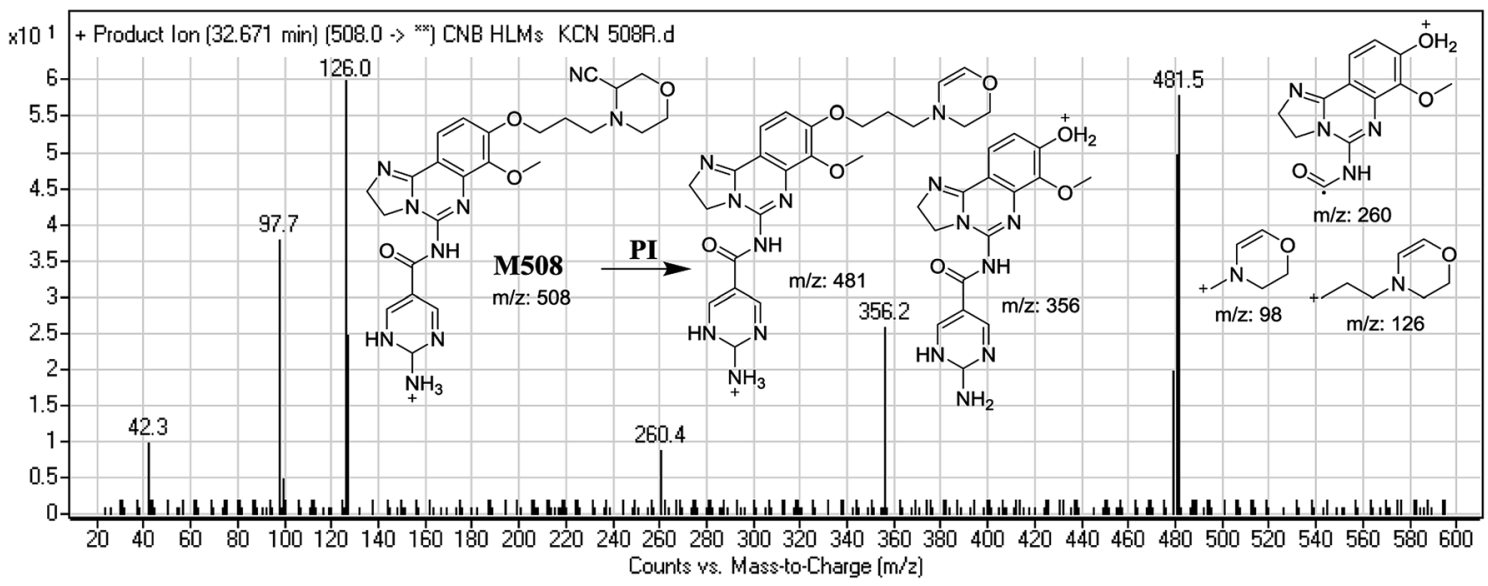

Fig. 9 Mass spectrum of M508 and its MS/MS fragments.

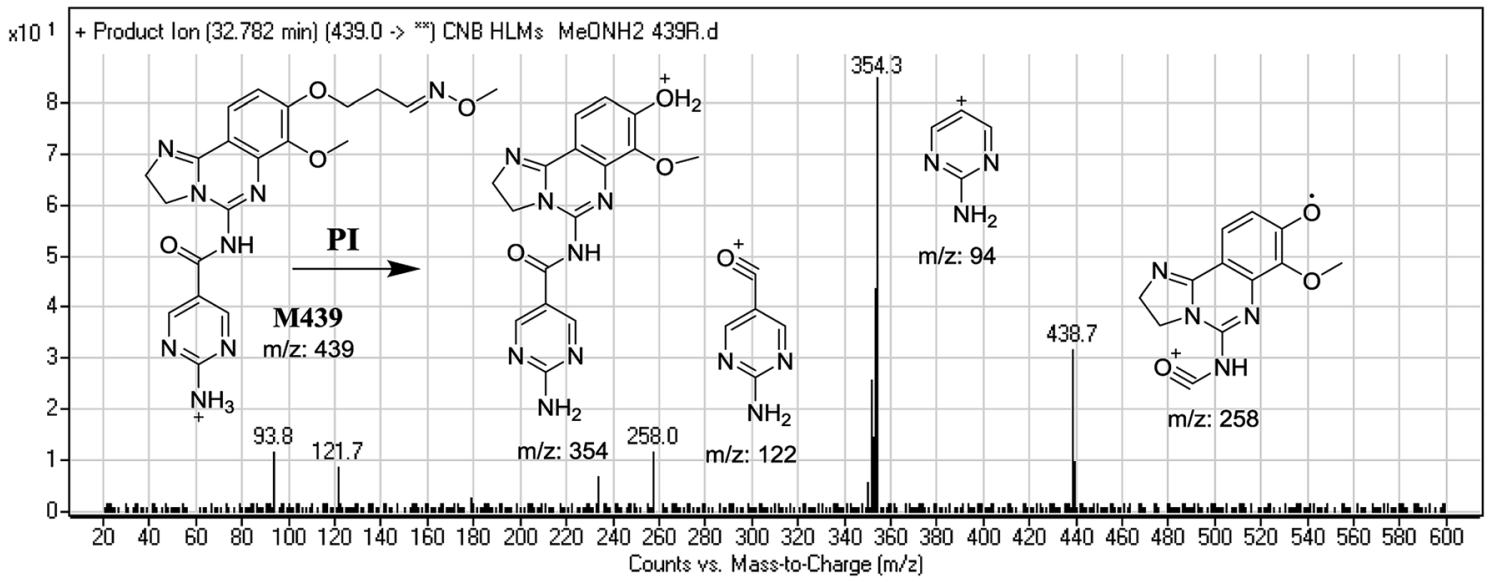

Fig. 10 Mass spectrum of M439 at $\mathrm{m} / \mathrm{z} 439$ and its MS/MS fragments.

3.3.3. Identification of M439 methoxyamine conjugate of CNB. M439 PIP appeared as $[\mathbf{M}+\mathrm{H}]^{+}(m / z 439)$ at $32.8 \mathrm{~min}$. F of PI at $m / z 439$ resulted in DRs at $m / z 354, \mathrm{~m} / z$ 258, $\mathrm{m} / \mathrm{z} 122$, and $\mathrm{m} /$ $z$ 94. DR at $\mathrm{m} / z 354$ indicated the formation of an oxime and suggested that all metabolic reactions occurred on the morpholine ring matching the three DRs (Fig. 10).
3.3.4. Identification of M512 methoxyamine conjugate of CNB. M512 PIP appeared as $[\mathbf{M}+\mathbf{H}]^{+}(m / z 512)$ at $32.8 \mathrm{~min}$. F of PI at $m / z 512$ resulted in DRs at $m / z 354, m / z 272$, and $m / z 131$. DR at $m / z 354$ suggested that an oxime was formed and all metabolic reactions occurred on the morpholine ring, which matched the other two DRs'. DR at $m / z 131$ indicated the

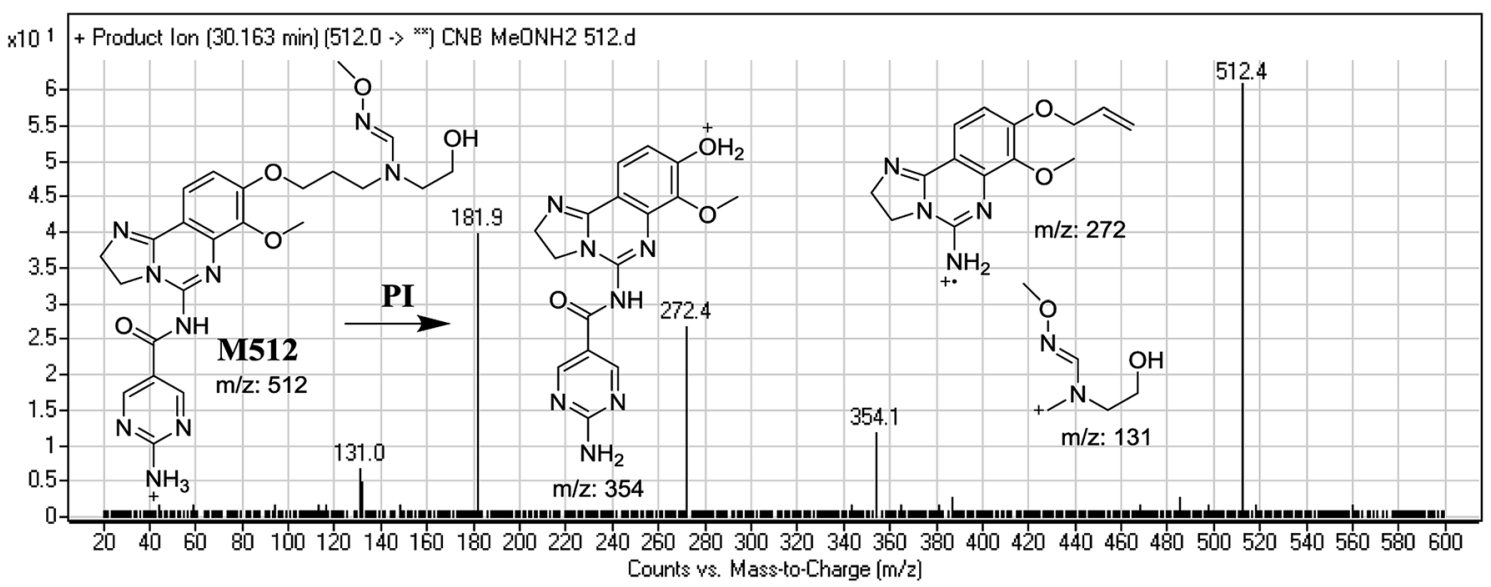

Fig. 11 Mass spectrum of M512 at $\mathrm{m} / \mathrm{z} 512$ and its MS/MS fragments. 
dealkylation and oxidative opening of the morpholine ring, resulting in oxime with an aldehyde (Fig. 11).

\subsection{Mechanism of CNB bioactivation}

The generation of M506 and M508 cyanide adducts confirmed the formation of iminium intermediates, and hydroxylation of the piperazine ring in CNB followed by the loss of a water molecule created unstable iminium electrophiles that could be captured by a cyanide nucleophile to form a stable adduct (Scheme 1). The mechanism of the formation of the iminium intermediate and CNB

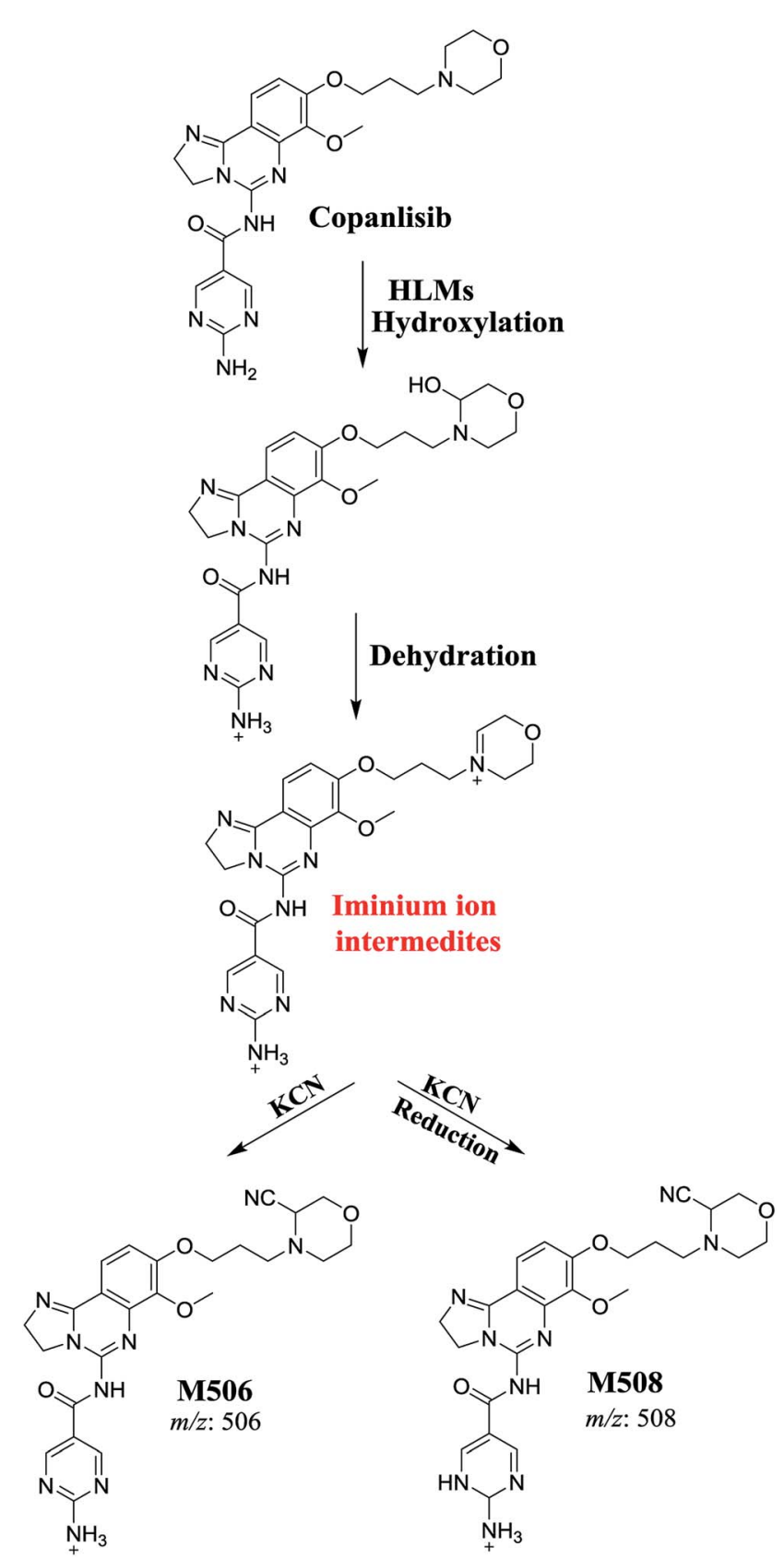

Scheme 1 Proposed mechanism for the formation of iminium intermediates in CNB metabolism and the potential trapping strategy. bioactivation have been previously studied in cyclic tertiary amine-containing drugs. ${ }^{33-38}$

The formation of M439 and M512 confirmed the production of aldehyde intermediates in CNB metabolism. The aldehyde electrophiles were formed by oxidative dealkylation<smiles>COc1c(OCCCN2CCOCC2)ccc2c1N=C(NC(=O)c1cnc(N)nc1)N1CCN=C21</smiles><smiles>[Y][C@H]1CCCN2CCOCC2C1</smiles><smiles>[3H]C1CCCCC1C</smiles>

HLMs<smiles>COc1c(OCCC=O)ccc2c1N=C1CCN=C12</smiles>

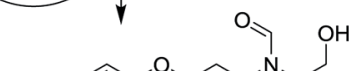
O $\mathrm{NH}$ intermediates<smiles>CN(OC(=O)c1cnc(N)nc1)C(=O)ON</smiles><smiles>COc1c(OCCCN(C)CCO)ccc2c1N=C1CCN=C12</smiles>

Scheme 2 Proposed mechanism of aldehyde generation.

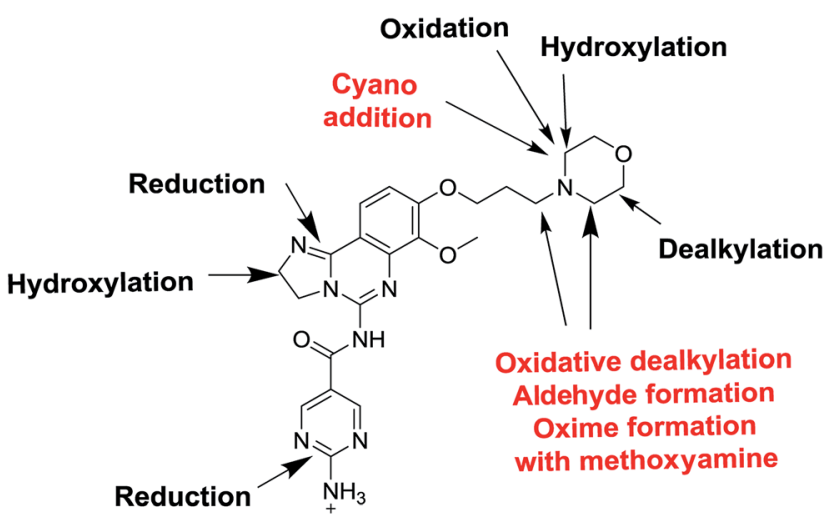

Copanlisib

Fig. 12 Chemical structure of copanlisib. Sites of phase I metabolic reactions and pathways of bioactivation are indicated by arrows. 
and captured with methoxyamine-forming oxime (M439 and M512). Oxidative dealkylation of the morpholine group formed an aldehyde captured by methoxyamine-forming M439. The opening of the morpholine ring by oxidative dealkylation resulted in aldehyde entrapment via M512 formation. Both oximes were stable, and were identified using LC-MS/MS (Scheme 2). Aldehyde formation in morpholine group-containing drugs has been described previously. ${ }^{39,40}$

\section{Conclusions}

Seven phase I metabolites, 2 cyano adducts, and 2 methoxyamine adducts of CNB were detected (Fig. 12). All pathways for the reactive metabolites depended on the morpholine group of $\mathrm{CNB}$, which may be associated with the side effects caused by CNB. These results have provided relevant groundwork for further investigations on CNB toxicity. Profiling of phase I metabolites is very crucial as it may be the next generation drugs. Understanding the bioactivation pathways is crucial to identify bioactive soft spots. Isosteric replacement or steric hindrance groups at these locations may block bioactivation and retain the pharmacological activity. Therefore, using the aforementioned data will help to develop next-generation drugs with less adverse effects.

\section{Conflicts of interest}

The authors declare no conflict of interest.

\section{Acknowledgements}

The authors would like to extend their sincere appreciation to the Deanship of Scientific Research at King Saud University for funding this work through the Research Group Project No., RGP-1438-045.

\section{References}

1 Y. Oki, M. Fanale, J. Romaguera, L. Fayad, N. Fowler, A. Copeland, F. Samaniego, L. W. Kwak, S. Neelapu, M. Wang, L. Feng and A. Younes, Br. J. Haematol., 2015, 171, 463-470.

2 E. Curran and S. M. Smith, Curr. Opin. Oncol., 2014, 26, 469475.

3 K. Balakrishnan, M. Peluso, M. Fu, N. Y. Rosin, J. A. Burger, W. G. Wierda, M. J. Keating, K. Faia, S. O'Brien, J. L. Kutok and V. Gandhi, Leukemia, 2015, 29, 1811-1822.

4 F. Morschhauser, D. Bron, K. Bouabdallah, U. Vitolo, K. Linton, E. Van Den Neste, S. Mappa, M. Giurescu, B. H. Childs and P. L. Zinzani, Blood, 2013, 122, 87.

5 E. Curran and S. M. Smith, Curr. Opin. Oncol., 2014, 26, 469475.

6 C. Massacesi, E. di Tomaso, N. Fretault and S. Hirawat, Ann. N. Y. Acad. Sci., 2013, 1280, 19-23.

7 W. A. Denny, Expert Opin. Ther. Pat., 2013, 23, 789-799.

8 A. Markham, Drugs, 2014, 74, 1701-1707.
9 W. J. Scott, M. F. Hentemann, R. B. Rowley, C. O. Bull, S. Jenkins, A. M. Bullion, J. Johnson, A. Redman, A. H. Robbins, W. Esler, R. P. Fracasso, T. Garrison, M. Hamilton, M. Michels, J. E. Wood, D. P. Wilkie, H. Xiao, J. Levy, E. Stasik, N. Liu, M. Schaefer, M. Brands and J. Lefranc, ChemMedChem, 2016, 11, 1517-1530.

10 N. Liu, B. R. Rowley, C. O. Bull, C. Schneider, A. Haegebarth, C. A. Schatz, P. R. Fracasso, D. P. Wilkie, M. Hentemann, S. M. Wilhelm, W. J. Scott, D. Mumberg and K. Ziegelbauer, Mol. Cancer Ther., 2013, 12, 2319-2330.

11 M. Will, A. C. Qin, W. Toy, Z. Yao, V. Rodrik-Outmezguine, C. Schneider, X. Huang, P. Monian, X. Jiang, E. de Stanchina, J. Baselga, N. Liu, S. Chandarlapaty and N. Rosen, Cancer Discovery, 2014, 4, 334-347.

12 A. Markham, Drugs, 2017, 77, 2057-2062.

13 A. Patnaik, L. Appleman, A. Tolcher, K. Papadopoulos, M. Beeram, D. Rasco, G. Weiss, J. Sachdev, M. Chadha and M. Fulk, Ann. Oncol., 2016, 27, 1928-1940.

14 D. C. Evans, A. P. Watt, D. A. Nicoll-Griffith and T. A. Baillie, Chem. Res. Toxicol., 2004, 17, 3-16.

15 A. S. Kalgutkar, D. K. Dalvie, J. P. O'Donnell, T. J. Taylor and D. C. Sahakian, Curr. Drug Metab., 2002, 3, 379-424.

16 U. A. Boelsterli, Curr. Drug Metab., 2002, 3, 439-450.

17 S. R. Knowles, J. Uetrecht and N. H. Shear, Lancet, 2000, 356, 1587-1591.

18 C. Ju and J. Uetrecht, Curr. Drug Metab., 2002, 3, 367-377. 19 S. Ma and M. Zhu, Chem.-Biol. Interact., 2009, 179, 25-37.

20 A. F. Stepan, D. P. Walker, J. Bauman, D. A. Price, T. A. Baillie, A. S. Kalgutkar and M. D. Aleo, Chem. Res. Toxicol., 2011, 24, 1345-1410.

21 L. P. Masic, Curr. Drug Metab., 2011, 12, 35-50.

22 Z. Zhang, Q. Chen, Y. Li, G. A. Doss, B. J. Dean, J. S. Ngui, M. Silva Elipe, S. Kim, J. Y. Wu, F. Dininno, M. L. Hammond, R. A. Stearns, D. C. Evans, T. A. Baillie and W. Tang, Chem. Res. Toxicol., 2005, 18, 675-685.

23 B. K. Park, A. Boobis, S. Clarke, C. E. Goldring, D. Jones, J. G. Kenna, C. Lambert, H. G. Laverty, D. J. Naisbitt and S. Nelson, Nat. Rev. Drug Discovery, 2011, 10, 292-306.

24 M. W. Attwa, A. A. Kadi, H. W. Darwish, S. M. Amer and N. S. Al-shakliah, Chem. Cent. J., 2018, 12, 99.

25 D. Ross, Pharmacol. Ther., 1988, 37, 231-249.

26 S. Ma and R. Subramanian, J. Mass Spectrom., 2006, 41, 1121-1139.

27 A. Tolonen, M. Turpeinen and O. Pelkonen, Drug discovery today, 2009, 14, 120-133.

28 M. Gerisch, T. Schwarz, D. Lang, G. Rohde, S. Reif, I. Genvresse, S. Reschke, D. van der Mey and C. Granvil, Cancer Chemother. Pharmacol., 2017, 80, 535-544.

29 M. W. Attwa, A. A. Kadi, H. W. Darwish and H. Alrabiah, Clin. Chim. Acta, 2018, 482, 84-94.

30 A. A. Kadi, R. F. Angawi, M. W. Attwa, H. W. Darwish and A. S. Abdelhameed, J. Chem., 2013, 2013, 905704.

31 H. A. Abdel-Aziz, W. M. Eldehna, A. B. Keeton, G. A. Piazza, A. A. Kadi, M. W. Attwa, A. S. Abdelhameed and M. I. Attia, Drug Des., Dev. Ther., 2017, 11, 2333-2346.

32 A. A. Kadi, A. S. Abdelhameed, H. W. Darwish, M. W. Attwa and A. H. Bakheit, Trop. J. Pharm. Res., 2016, 15, 2683-2692. 
33 A. A. Kadi, H. W. Darwish, M. W. Attwa and S. M. Amer, $R S C$ Adv., 2016, 6, 72575-72585.

34 S. Amer, A. A. Kadi, H. W. Darwish and M. W. Attwa, RSC Adv., 2017, 7, 4479-4491.

35 M. W. Attwa, A. A. Kadi, H. Alrabiah and H. W. Darwish, J. Pharm. Biomed. Anal., 2018, 160, 19-30.

36 M. W. Attwa, A. A. Kadi and A. S. Abdelhameed, J. Pharm. Biomed. Anal., 2019, 164, 659-667.
37 A. A. Kadi, H. W. Darwish, H. A. Abuelizz, T. A. Alsubi and M. W. Attwa, R. Soc. Open Sci., 2019, 6, 181714.

38 M. W. Attwa, A. A. Kadi and A. S. Abdelhameed, RSC Adv., 2018, 8, 38733-38744.

39 X. Liu, Y. Lu, X. Guan, B. Dong, H. Chavan, J. Wang, Y. Zhang, P. Krishnamurthy and F. Li, Biochem. Pharmacol., 2015, 97, 111-121.

40 A. A. Kadi, S. M. Amer, H. W. Darwish and M. W. Attwa, $R S C$ Adv., 2017, 7, 36279-36287. 